\title{
ANÁLISE DAS AÇÕES EM EDUCAÇÃO AMBIENTAL REALIZADAS EM UMA COMUNIDADE DO MUNICÍPIO DE VITÓRIA DE SANTO ANTÃO (PE)
}

Mirelle Jeniffer Ferreira de Lima ${ }^{1}$ Florisbela de Arruda Camera e Siqueira Campos ${ }^{2}$

Luiz Miguel Picelli Sanches ${ }^{3}$

Resumo: O presente estudo analisa a compreensão dos moradores do bairro de Redenção no município de Vitória de Santo Antão - PE, sobre as ações de Educação Ambiental realizadas na comunidade. Trata-se de um estudo descritivo, exploratório, com abordagem qualitativa, organizada segundo a técnica de Bardin, através da análise de conteúdo. Os resultados permitiram entender que a amostra de pesquisa avaliada é concordante na insatisfação com a descontinuidade da ação de Educação Ambiental da Agência Municipal do Meio Ambiente da Vitória de Santo Antão (AMAVISA), bem como acredita que por conta dessa descontinuidade, a ação como um todo de pouco ou nada valeu, pois não foi capaz de fomentar na população local uma conscientização efetiva sobre o meio ambiente. Além disso, sobre o conhecimento da população em relação à coleta seletiva e reciclagem, nota-se pouco conhecimento no geral, justamente o tema que foi eleito pela AMAVISA na ação de Educação Ambiental.

Palavras-chave: Educação Ambiental; Meio Ambiente; Coleta Seletiva; Reciclagem.

\footnotetext{
1 Enfermeira graduada pela Universidade Federal de Pernambuco-Centro Acadêmico de Vitória, mestre em Saúde Humana e Meio Ambiente pela UFPE-CAV. E-mail: luajeniffer@gmail.com

2 Nutricionista graduada pela Universidade Federal de Pernambuco, mestre em Nutrição pela UFPE, doutora em Nutrição pela UFPE. E-mail: florisbelacampos55@gmail.com

${ }^{3}$ Enfermeiro graduado pela Universidade Estadual de Maringá, Mestre e Doutor em Enfermagem pela Universidade Estadual de Campinas. E-mail: luiz.sanches.ufpe@gmail.com Revbea, São Paulo, V,13, № 1: 344-363, 2018.
} 


\section{Introdução}

O presente estudo parte da análise de uma situação-problema encontrada na cidade de Vitória de Santo Antão (PE), relacionada à questão da Educação Ambiental, visto que em alguns bairros localizados na zona urbana da cidade de Vitória de Santo Antão, prevalece o cenário de poluição, descarte inadequado do lixo, ausência de saneamento básico, arborização escassa, entre outras problemáticas ambientais. A observação dessa realidade na cidade de Vitória de Santo Antão, desencadeou o desenvolvimento dessa pesquisa e foi no sentido de buscar uma razão para essa situação de descaso sócio ambiental que o pesquisador buscou informações sobre essa situação junto ao órgão estadual responsável pela manutenção ambiental da cidade, a Agência Municipal de Meio Ambiente da Vitória (AMAVISA). Esse órgão governamental, a AMAVISA, possui, entre suas incumbências, a mais importante para este estudo, trata-se do processo de Educação Ambiental.

Em 2015 a AMAVISA informou sobre a criação da coleta seletiva e da Campanha "Limpa Vitória: coleta seletiva e solidária", que envolveria diversas ações de Educação Ambiental em seu bojo. Foi selecionado apenas um bairro para iniciar o projeto piloto da agência, Redenção. Em posse dessas informações se do cenário problemático da cidade de Vitória de Santo Antão, dois (2) anos após a implantação da coleta seletiva, partiu-se para o bairro, a fim de ouvir e analisar a compreensão dos moradores sobre essas ações de Educação Ambiental realizadas na comunidade.

A justificativa desse estudo é conhecer sobre as dificuldades, os impactos e o efeitos de uma ação de Educação Ambiental, buscando gerar subsídios para fomentar diversos estudos sobre o tema e também para a implantação de novas ações de Educação Ambiental.

\section{Materiais e Métodos}

Trata-se de um estudo descritivo, exploratório, com abordagem qualitativa, pois este tipo de abordagem permite aprofundar-se sobre um determinado assunto, tornando-o mais compreensível e direcionando melhor a pesquisa (GIL, 2008). O estudo foi realizado num bairro da zona urbana do município de Vitória de Santo Antão (PE), Redenção. A população foi formada por moradores da comunidade do bairro de Redenção, que participaram das ações de Educação Ambiental realizadas pela AMAVISA. O número de participantes da pesquisa foram seis (6) e a amostra foi definida através da saturação teórica. O instrumento para coleta de dados utilizado para a população deste estudo, tratou-se de um roteiro de entrevista semiestruturado elaborado pela autora contendo uma pergunta disparadora: O que esta (s) atividade (s) de Educação Ambiental que o senhor (a) participou pretendia na sua opinião? A seleção dos participantes da pesquisa foi realizada nos locais específicos (Escola estadual, estabelecimentos comerciais e residenciais) que fizeram parte da área de abrangência das ações de Educação Ambiental realizadas pela AMAVISA, dados estes fornecidos pela própria agência. Os dados obtidos 
mediante a realização da entrevista semiestruturada foram gravados (apenas o áudio). Após esse momento os dados foram transcritos integralmente. A análise de conteúdo foi organizada em três etapas cronológicas: Pré-análise; Exploração do material e Tratamento dos resultados, a inferência e a interpretação (BARDIN, 2010).

\section{Resultados}

\section{Descrição das atividades da AMAVISA}

Em 2015 a AMAVISA implantou no bairro de Redenção em Vitória de Santo Antão - PE o projeto piloto de coleta seletiva e Campanha "Limpa Vitória: coleta seletiva e solidária" As ações da campanha foram conduzidas por meio da Escola Estadual Madre Lucila Magalhães, localizada no próprio bairro. Fizeram parte do projeto alguns alunos representantes das turmas das últimas séries dos ensinos fundamental e médio, além da participação de moradores e comerciantes locais.

Além disso, ocorreram algumas ações da campanha na sede da Associação de Moradores do bairro, em estabelecimentos comerciais e com representantes e também de porta em porta em algumas ruas do bairro. Tais intervenções contaram com palestras sobre Resíduos Sólidos Urbanos, que tinham o objetivo de debater sobre a problemática dos resíduos e sensibilizar os moradores, alunos, comerciantes e toda a comunidade, sobre os potenciais danos causados ao meio ambiente devido ao descarte indevido desses. A campanha foi divulgada por meio da página da AMAVISA, no facebook, bem como em programas de rádio da cidade e carros de som que passavam pelos locais das ações com antecedência, informando sobre elas.

Nas palestras que aconteceram no local, foram exibidas algumas fotos do bairro de Redenção em que eram vistos problemas ambientais, como descarte irregular de lixo, poluição, falta de arborização, etc. Essas imagens foram a fim de incluir os próprios moradores no debate. Para tanto, utilizaram-se recursos multimídia, materiais educativos elaborados pela própria AMAVISA - como cartazes, panfletos, faixas, etc. - e os participantes receberam brindes após as palestras - bonés, sacolas de lixo para automóveis, camisetas, etc.

No bairro de Redenção, ainda como parte da ação de Educação Ambiental empreendida, foram instalados três Pontos de Entrega Voluntária (PEV), um deles localizado na entrada do bairro, outro na praça pública e um próximo às igrejas locais. A intenção na instalação desses PEV, foi facilitar o acesso aos moradores e estimular a coleta seletiva de resíduos (AZEVEDO, 2016).

Com quase um ano de implementação do projeto de Educação Ambiental coleta seletiva e da Campanha "Limpa Vitória: coleta seletiva e solidária", em 2016, retornou-se ao bairro de Redenção a fim de avaliar se o cenário havia passado por mudanças e como o programa favorecera a questão ambiental no local, porém os resultados não foram inicialmente visíveis, bem como 
mudanças na questão ambiental da cidade. Por isso a AMAVISA foi indagada e a mesma confirmou a interrupção das ações de Educação Ambiental. A agência, nessa ocasião, informou que o projeto e as ações de 2015 foram descontinuados, bem como não haveriam mais ações voltadas à Educação Ambiental ou à coleta de lixo depositado nos PEV do bairro. A justificativa do órgão para essa descontinuidade do projeto foi a falta de comprometimento da prefeitura da cidade em relação a parcerias que fortalecessem essas ações. Além disso, a agência informou que a prefeitura da cidade deixou de disponibilizar caminhões específicos para fazer a coleta dos resíduos nesses pontos e também se descompromissou da responsabilidade de dar um destino final aos resíduos coletados.

As entrevistas que foram empreendidas junto a esses residentes de Redenção, se deram no sentido de debater com essa comunidade sobre as ações de Educação Ambiental realizadas no bairro, buscando entender sua percepção perante esses programas, além de tentar visualizar alguns resquícios de consciência ecológica que possa ter restado após a ocorrência dos eventos de 2015 e, ainda, de abordar se e como a descontinuidade do projeto afetou essa comunidade. Dadas as entrevistas, emergiram três (3) categorias descritas a seguir:

\section{1a. Categoria: Resultados da ação de Educação Ambiental da AMAVISA}

O primeiro entrevistado disse não saber qual era a finalidade da ação, então, foi questionado sobre o que achou sobre a ação. Sua resposta foi que algumas pessoas disseram para separar produtos recicláveis dos não recicláveis, pois eram tipos diferentes a ser separados nos PEV. Esse entrevistado, inclusive, disse que ele mesmo chegou a esvaziar diversas vezes os PEV, colocando os resíduos em seu carro e levando-os. Nesse ponto, vale observar que, mesmo dada a descontinuidade da ação, os PEV continuam espalhados pelo bairro, contudo, o caminhão de coleta seletiva não passa mais pelo local e, portanto, não faz a coleta desses resíduos, que ficam acumulados nas lixeiras dos PEV. O entrevistado alega que ele mesmo retira o lixo dos pontos e deposita em áreas cujos caminhões de coleta comuns passam.

$\mathrm{Na}$ segunda entrevista, ao perguntar sobre a pretensão da atividade da AMAVISA, a entrevistada disse acreditar que foi o presidente da associação de moradores quem implementou a ação, e que sua intenção era organizar a limpeza em frente à sede da associação no bairro de Redenção. Mas, embora dada essa intenção, a entrevistada comenta que a população continua descartando lixo no chão e também não separa de forma adequada os materiais recicláveis. Observa-se que, apesar de ser informada de que a ação da AMAVISA teve somente o apoio do presidente da associação de moradores do bairro, há a insistência de sua parte que a ação foi somente articulada pelo presidente da associação de moradores, desprezando totalmente a ação da AMAVISA. 
$\mathrm{Na}$ terceira entrevista ao ser questionada sobre o qual acreditava ser a pretensão dessa ação, respondeu que a pretensão era melhorar a qualidade de vida da comunidade, mostrar a forma correta de lidar com o lixo e de colocá-lo no local adequado, em suma, de melhorar o esclarecimento da população em relação à questão ambiental. Ao ser perguntada se isso deu certo, a moradora acredita que sim, em alguns pontos, ao menos no sentido de esclarecer dúvidas sobre doenças, entre outros pequenos esclarecimentos. Até esse momento, observa-se que a entrevistada reflete e oferece respostas incertas, mas, tenta resumir e fazer uma organização mental de lembranças e percepções sobre as ações.

Sobre a conscientização e práticas adequadas de coleta seletiva na comunidade, ainda a terceira entrevistada, informa que seu lixo reciclável ela separa para um catador de materiais recicláveis específico que passa na região. Explica então que faz a separação do lixo em casa, já separando os recicláveis para o catador. Nesse momento, assim como foi observado ao falar com outros moradores, é possível notar que a presença de catadores de resíduos autônomos no bairro é comum. Como essa entrevistada demonstra saber selecionar o lixo para enviar para a reciclagem, mas nem menciona os PEV, nota-se que esses catadores estão ocupando a lacuna deixada pelo programa público. Quando se pergunta que se ela, a terceira entrevistada, acha que a ação já fora esquecida por parte da comunidade, responde de forma afirmativa, acreditando que na hora a população até se compromete, mas, insiste que se não houver continuidade nessas ações de Educação Ambiental, dificilmente haverá a mudança de consciência, de atitude por parte da comunidade. Sobre as ações de Educação Ambiental, a entrevistada comenta que:

Eu acho que deveria ser mais divulgada, bem mais trabalhada e que esse evento fosse mais frequente, porque aqui, eu acho que teve esse e acho que eu lembro que faz muito tempo que teve outro [...] eu nem sei se teve outro [...] eu acho que nem teve [...] eu acho que foi o primeiro. Eu acho que são coisas [Educação Ambiental] que eu sei que não dá pra está fazendo constantemente, Mas assim [...] Que por ano. Porque eu acho que quando tiver uma agora vai ser daqui a não sei quantos anos, né?! Eu acho que devia ser mais frequente. Da maneira deles, eu acho que deveria ser mais frequente e que fosse uma coisa mais divulgada, porque eu acho que a Educação Ambiental, que era uma coisa que teria que ser nossa, mas como pra muitos é uma coisa que tem que está divulgando

(Entrevistada 3, 2017).

A entrevistada demonstra bastante coerência em sua crença sobre a importância da Educação Ambiental como uma parcela da própria educação familiar, que deveria ser algo criado no sujeito desde cedo. Contudo, compreende que nem todas as pessoas possuem tal esclarecimento ou oportunidade para gerar esse tipo de educação no bojo familiar. Por essa razão, Revbea, São Paulo, V,13, № 1: 344-363, 2018. 
entende que essas pessoas precisam de apoio para alcançar esse tipo de consciência, para que sejam realmente educadas e efetivem uma mudança real de atitudes. Para tanto, se faz necessário implementar e persistir nas ações de Educação Ambiental, empreendendo-as com frequência, fazendo delas uma rotina que torne esse processo educacional permanente. A moradora relata, de forma frustrada, que somente soube de uma ação de Educação Ambiental no bairro, fez sua participação, mas que nunca mais ouviu nada relacionado para essa comunidade. Bem como, habituada ao esquecimento do bairro, acredita que algo parecido deve demorar muito a acontecer novamente na região, o que intensifica sua decepção com a descontinuidade do projeto.

Na quarta entrevista, o morador afirma acreditar que a AMAVISA auxilia a comunidade com a oferta de palestras, uma iniciativa que encara como fundamental, porém, acredita que devido à falta de continuidade da Educação Ambiental fora desses momentos pontuais, favorece o não êxito dos resultados da ação:

A AMAVISA ajuda muito com as palestras, uma ajuda muito boa, uma iniciativa que pra mim é essencial, mas como a gente sabe, quando a criança vai pra escola ela vai aprender português, matemática, história, geografia [...]. E ela não vai aprender a educação como pessoa. Primeiramente a educação como pessoa parte de casa e nas escolas ela vai aprender matérias, vai aprender pra futuramente ter um bom trabalho. E esse trabalho que tem em casa, que é um trabalho de consciência humana, né?! Tipo, você vai para o colégio e vai quebrar uma banca, uma cadeira? Eu acho que quem tem uma educação de casa não vai pra escola pra quebrar uma cadeira. Se você tem de casa uma coisa feito [...] "Ah, eu não vou quebrar uma cadeira!". Você também não vai quebrar uma lixeira [sic.] (Entrevistado 4, 2017).

O entrevistado comenta que a Educação Ambiental é algo que deve formar parte da educação familiar, pois na escola é possível adquirir conhecimentos, mas os valores pessoais são adquiridos em casa. O morador compara atos de vandalismo como quebrar uma carteira na escola, aos atos de quebrar lixeiras nas ruas, alegando que essa questão é desencadeada pela ausência de educação no âmbito familiar, da fragilidade na construção de valores pessoais do sujeito.

Na quinta entrevista, a moradora diz que a pretensão dessa ação era educar a população sobre reciclagem, meio ambiente, entre outras coisas relacionadas. Quanto aos resultados da ação, acredita que não houveram grandes mudanças: 
Eu acho que pretendia educar a população em relação a reciclagem, Educação Ambiental, essas coisas [...] na realidade eu acredito que não funcionou muito não, porque a maioria do pessoal não faz o certo, não vai lá e coloca o plástico, vidro [...] tudo separado, não. Acho que tentaram educar, mas que não foi válido, na minha opinião. Que eu vejo que a ação do povo foi nenhuma. Não teve nenhuma não (Entrevistada 5, 2017).

A entrevistada enfatiza que sua percepção sobre os resultados da ação da AMAVISA foi de que a Educação Ambiental na população do Redenção não foi efetivada, pois não foi capaz de causar uma mudança nos hábitos da comunidade em relação à forma como lidam com as questões ambientais.

Na sexta e última entrevista, o entrevistado fala sobre os resultados que acredita terem sido alcançados com as ações da agência, informa que a pretensão clara era de que houvesse uma conscientização sobre a separação do lixo para reciclagem, mas que a descontinuidade do projeto fez com que fosse esquecido o propósito por parte dos moradores.

Pretendiam [...] de acordo com o lixo que vem sendo acumulado tudo junto, pretendiam separar pra ter mais reciclagem até porque pra o meio ambiente isso é bom, né?! $E$ através dos anúncios o pessoal fica mais educado pra fazer isso, falta mais anúncios pra o pessoal está sempre lembrando [...] a cada 2 meses [...] a cada 3 meses [...] pra o pessoal tá sempre lembrando, se não esquece. Isso aí faz muito tempo [a ação de Educação Ambiental] e o povo já esqueceu [sic.] (Entrevistado 6, 2017).

O entrevistado reconhece a boa intenção da AMAVISA na tentativa de conscientizar a população sobre reciclagem, especialmente em vista dos problemas relacionados ao lixo no bairro. O meio pelo que se sentiu mais afetado pela ação, foi ouvir orientações no carro de som, bem como por meio da entrega de panfletos e folders. Em sua opinião essa forma foi eficaz para a Educação Ambiental, porém, deveria ocorrer periodicamente e não somente de forma pontual.

\section{Categoria: O que a ação da AMAVISA alcançou}

Prosseguindo as entrevistas, perguntou-se então para que a atividade empreendida serviu. A resposta do primeiro entrevistado foi de que a percepção geral da comunidade é de que não serviu para nada, que inclusive questionam a permanência dos PEV no bairro, já que o lixo não é coletado. Insistindo em perguntar sobre o que ele acredita que a AMAVISA pretendia com o programa, o entrevistado se atém à implantação dos PEV, à tentativa de conscientizar a população sobre depositar seu lixo naqueles locais para que a reciclagem viesse fazer a coleta, ainda consolida o fato de que isso ocorreu poucas vezes e 
simplesmente cessou. $\mathrm{O}$ entrevistado se detém fortemente ao fato da ausência de coleta nos PEV, o que demonstra sua indignação e a necessidade de dar a atenção necessária a essa problemática. Considerando sua revolta com a situação dos PEV, perguntou-se se o entrevistado tinha algo a dizer sobre a situação do bairro, sobre a coleta de lixo, ao que comentou:

O que vão botando ali eu vou tirando, pode ir lá olhar que não tem nada dentro não, eu já tirei tudo. Tinham deixado aí um saco carregado de litro [...] tinha um saco com 35 litros de Teacher, botaram dentro e tava [sic] cheio, aí eu tirei os litros todinhos, tá aí o saco cheio [...] As vezes seu [Fulano] pega pra botar misturado os litros que não servem: Alcatrão, Montilla, tudo que é litro que não serve eu chego, boto tudo dentro do saco e fico esperando o lixão [Caminhão de coleta de lixo comum], e tanto boto que eu faço a limpeza e os meninos chega dizem 'Dr. Elias [...]' [Prefeito anterior], Agora não! Que agora é Aglailson [Atual prefeito], 'Dr. Elias vai te dar um salário todo mês!'. Dinheiro pra eu fazer isto! [sic] (Entrevistado 1, 2017).

Depois dessa declaração, perguntou-se porque então o homem faz essa limpeza, ao que respondeu que se não for ao local retirar o lixo e levá-lo para locais de alcance do caminhão de coleta comum, os PEV ficam abarrotados de resíduos. Então, debatendo essa questão com o entrevistado, concordou-se que, se o programa funcionasse como fora prometido, seria positivo tanto para ele quanto para a comunidade. Questionou-se então por qual razão ele acredita que se o programa estivesse em execução, favoreceria sua vida. Ao que respondeu que ajudaria a retirar todo o lixo que estava espalhado pela praça, uma vez que o PEV localizado nela estava abarrotado.

A segunda entrevistada prosseguiu dizendo que não houve efetividade na ação, pois as pessoas continuar a não colocar o lixo nas lixeiras. Perguntou-se por que ela acredita que isso não acontece, ao que responde que isso pode ser "falta de educação", acredita ainda que falta um processo de reeducação da comunidade, já que a instalação das lixeiras foi de que as pessoas não jogassem lixo no chão, mas que também depende dos moradores controlarem a forma como lidam com sua própria sujeita. Nessa parte da entrevista, é possível notar que a entrevistada delega toda a responsabilidade do fracasso da ação da coleta seletiva no bairro à própria comunidade local. Parece desconhecer o fato de que o caminho de coleta específico não passa mais pelo local, mas, em um segundo momento ela demonstra ter conhecimento disso, mantendo a posição de que a coleta não ocorre mais porque a comunidade não colabora, não faz sua parte.

A terceira entrevistada alega que sua prática individual de separação de lixo e envio de materiais para a reciclagem já era uma ação que ela fazia antes do programa da AMAVISA. Acredita que a ação auxiliou algumas pessoas em relação à conscientização, mas nem todas possuem essa formação de consciência, também que, embora a comunidade seja envolvida nessas ações, a prática da conscientização e as ações de coleta seletiva e reciclagem são

revista brasileira educação ambiental 
responsabilidades individuais, já que cada pessoa decide como aproveitará melhor o processo de Educação Ambiental. A moradora acredita que mesmo que o programa alcance somente algumas pessoas, mas que elas estejam interessadas e comprometidas com a mudança de atitudes, farão a diferença e terão importância significativa na comunidade. Sobre o que acrescentaria a ação de Educação Ambiental, a entrevistada responde:

[...] na minha opinião eles deveriam ter vindo antes, antes de colocar [PEV], porque eu mesmo, quando eu soube, vamos supor [...] já foi um dia antes, eu acho que deviam ter divulgado a mais tempo. Porque nos preparam e a gente até se programava mais né?! Programar um tempinho pra ir pra lá ver, ficar mais tempo, entendeu?! Eu achei que deveria ter sido mais anunciado, mais divulgado. Porque eu gosto de participar dessas coisas, quando tem, eu sempre participo [...] (Entrevistada 3, 2017).

Além de divulgar com antecedência a implementação da ação, a moradora prossegue dizendo que acredita na necessidade de manter 0 programa "em alta", continuar divulgando, já que uma única ação isolada não é suficiente para fomentar a Educação Ambiental, que deve ser contínua.

O quarto entrevistado acredita que as ações podem não ter alcançado seu objetivo, pois o ser humano como um todo não possui consciência suficiente para saber preservar algo que trará benefícios a ele mesmo. Pois a tomada de consciência seria fundamental para favorecer a efetivação das ações:

O que falta pra dar certo é o ser humano hoje saber que aquilo ali vai fazer bem pra ele, porque normalmente eles fazem esse trabalho de colocar as lixeiras, e é muito bom, certo?! Quando o ser humano tem consciência, porque hoje você coloca uma lixeira no meio da rua e no outro dia tá quebrada. Acho que pra essas pessoas [AMAVISA] fazerem a manutenção se gasta muito [...] Se cada pessoa tivesse a consciência de tá vendo aquela lixeira e deixar aquela lixeira lá intacta e usar devidamente ela, seria muito, muito, muito bom. E até pra gente tirar as coisas recicladas e colocar novamente como objetos e etc. e várias outras coisas, né?! Mas só que hoje o que tá faltando realmente é o ser humano ter mais consciência e não está fazendo vandalismo e quebrar, que é o a gente ver muito [sic.] (Entrevistado 4, 2017). 
Educação Ambiental não foi restrita ao seu bairro, já que fala mais das lixeiras de outros bairros do que dos PEV de Redenção.

A quinta entrevistada disse que as ações seriam mais efetivas se ocorressem mais palestras, bem como a firmação de parceria com a associação de moradores do bairro para empreender ações contínuas, já que a única ação ocorrida, sem continuidade, gerou poucos ou nenhum resultado efetivamente notável.

A gente tem uma associação de moradores aqui que é parada, que deveria ser mais trabalhada, deveriam ter chamado mais a população, a comunidade para estar unido, para fazer estas campanhas, mas é tudo muito parado, tudo muito vago [...] não tem nada aqui! Teve aquela ação, aquela ação mobilizou a comunidade e pronto, acabou, não teve mais nada! E em questão da reciclagem [PEV] que colocaram ali não serviu de nada, ficou mais pra enfeite mesmo, porque eu não vejo nada, eu nunca vi nem o pessoal fazer isso [separar o lixo] e nem a coleta [Caminhão de coleta seletiva] vim buscar. Eu nunca vi essa coleta de reciclagem aqui [...] colocou lá [os PEV] e lá ficou. Nessas coisas tem que trabalhar mais isso, né?! [sic.] (Entrevistada 5, 2017).

A entrevistada pontua, novamente, a questão da continuidade das ações de Educação Ambiental, dizendo que seria essa a solução para modificar efetivamente os hábitos da comunidade, uma questão que deveria partir, sobretudo, da associação de moradores, que deveria incluir a população nas atividades que realiza. A implementação da coleta seletiva em sua concepção, mobilizou a comunidade no momento inicial, mas devido à descontinuidade das ações e da não coleta dos caminhões especiais, a comunidade perdeu novamente o hábito de separar o lixo.

O sexto entrevistado disse que as ações funcionaram por conta dos anúncios feitos na época, mas ressalta a percepção dos demais entrevistados, de que quando os anúncios cessaram, as pessoas deixaram de empreender as ações conscientes, e passaram a acumular novamente o lixo, sem o processo de coleta seletiva, pensa que até mesmo quem fazia a coleta seletiva deixou de fazer quando a ação foi interrompida.

Deveriam se juntar novamente e honrar o compromisso da coleta passar, uma vez na semana, duas vezes por semana, aí talvez junto com os anúncios o pessoal se conscientize que precisam da reciclagem. Quando estavam anunciando eu ouvia o pessoal comentando no bairro, colocando os vidros separados, os plásticos... e quando parou os anúncios o pessoal começou a esquecer, aí eu fui vendo (Percebendo) que foi devido a isso aí mesmo, devido aos anúncios que não foram prolongados, foi só naquele período curto e depois esqueceram [...] aí o povo esqueceu também (Entrevistado 6, 2017). 
O entrevistado somente evidencia uma percepção que parece geral de toda a amostra, de que os prejuízos da descontinuidade da ação foi justamente fazer com que um hábito, ao invés de ser perpetuado, fosse totalmente esquecido. De forma que, sua crença é de que o processo de conscientização precisa ser longo e contínuo.

\section{3a Categoria: A criação da consciência ambiental}

$\mathrm{Na}$ tentativa de mensurar o nível de consciência ambiental que a ação da AMAVISA pode ter deixado nessa população, perguntou-se porque é importante fazer a reciclagem e não colocar todo o tipo de lixo junto, mas sim separá-lo. O primeiro entrevistado respondeu que o que tiver por ali vai para o mesmo lixo, tudo é colocado no mesmo local e confirma que nada é separado. Então pergunta-se se ele acredita que é importante separar o lixo, o homem responde que a comunidade gostaria de fazê-lo, mas que o caminhão viesse buscar e levasse ao local correto de reciclagem, o que não acontece. Ao final da primeira entrevista, fica bastante claro ao pesquisador que o entrevistado se encontra incomodado com a presença do lixo no PEV que não é regularmente coletado, deixando a ele que faça essa tarefa, se não quiser conviver com o local e as consequências do acúmulo de resíduos. O entrevistado, todavia, não demonstra conhecimentos sobre reciclagem e coleta seletiva, bem como parece ignorar a importância de separar os resíduos por tipos e descarta-los de forma devida. Ele enfatiza a sua revolta, já que foi lhe dito que o lixo depositado nos PEV receberia tratamento diferenciado, o que claramente não se cumpriu. Visando esse descumprimento do que foi prometido, o entrevistado faz por conta própria a coleta do lixo dos PEV.

A segunda entrevistada acredita que o presidente da associação de moradores deveria ter um foco maior nas necessidades do bairro, agindo e buscando apoio dos órgãos competentes para auxiliar nos problemas encontrados. Pois acredita que o bairro de Redenção somente é lembrado pelo poder público em período eleitoral, depois disso, é novamente esquecido. Em suas falas, nota-se também que a entrevistada se revolta pela ausência de medidas e políticas públicas direcionadas ao bairro, bem como cobra atitude dos líderes comunitários em cobrar e pressionar os órgãos públicos para gerar a implantação e continuidade de propostas. Ainda que a entrevistada mencione o abandono do bairro por parte dos políticos após os períodos eleitorais, continua atribuindo a responsabilidade à comunidade, alegando que a mesma não busca seus direitos e não tenta dar visibilidade aos problemas do bairro. Em sua perspectiva, uma pressão popular direcionada ao poder público, seria preponderante para beneficiar o bairro e gerar as ações necessárias. Durante a entrevista, questiona a ausência de árvores pela cidade, quando o pesquisador comenta que observou algumas nos quintais das casas, a entrevistada diz que alguns moradores plantam suas próprias árvores, mas que a cidade é ausente de arborização, relata que mesmo a praça da cidade, anteriormente repleta de árvores, passou por cortes e agora não possui mais arborização. 
Então, isso aí [...] As pessoas deveriam vim [sic] e ajudar [...] $A$ gente ver tanto por aí a fora, as crianças do colégio saem, no meio ambiente com as pessoas da ação social, vão plantar! Tira uma plantinha daqui pra [sic] plantar perto do rio, perto disso e daquilo outro [...] Fazendo uma nova... Como se diz? Eles estão fazendo com que a criança tenha responsabilidade naquilo que vai melhorar o universo! Para melhorar, a gente tem que fazer a nossa parte e aqui ninguém está fazendo a sua parte, a começar pelos governantes (Entrevistada 2, 2017).

Ao falar sobre os cortes das árvores que rodeavam a praça, a moradora se refere ao caso como um retrocesso ambiental, uma fala que demonstra a desconfiança gerada perante qualquer tentativa de ação que envolva Educação Ambiental. Isso se deve a não compreensão de empreender tais ações se não haverá continuidade. As ações são comparadas ao ato de cortar as árvores, levando à percepção de que a comunidade do bairro não está nem perto de ter uma Educação Ambiental adequada, o que se deve também à não continuidade das ações que são iniciadas junto a ela, isto é, nesse momento divide a responsabilidade entre o poder público e a comunidade.

Perante essas opiniões tão formadas, estimulou-se à segunda entrevistada a apontar quem seria mais culpado nessas falhas, se a comunidade ou o poder público. Ao que respondeu que certamente é o poder público que não dispõe de recursos para suprir os órgãos responsáveis pelos projetos, para que os agentes responsáveis por eles deem continuidade nos mesmos junto à comunidade. Dessa forma, prossegue dizendo que os que possuem maior poder aquisitivo passam a fazer investimentos próprios para a melhorar as condições, o que é a minoria da comunidade. O que a entrevistada questiona é justamente esse ponto, que na impossibilidade de tirar do próprio bolso para fazer algo pela comunidade no sentido ambiental, a maior parte da população simplesmente cruza os braços e deixa estar.

Aí fica difícil, a gente querer cobrar de Sicrano [presidente da sede] uma coisa que a gente sabe que ele não pode fazer, vontade ele tem, ele montou uma academia aí para fazer ginástica, para fazer as pessoas de maior idade fazer ginástica. Tem uma pessoa que ficou paga pra ser professor de zumba e pronto, na terça-feira ele [candidato político do bairro] paga e na quinta-feira já cortou, quer dizer que ele [candidato político do bairrol só queria o voto, depois que ganhou ele ainda ficou mantendo a terça-feira e a quinta-feira se a gente quiser a gente paga [sic] (Entrevistada 2, 2017).

Em síntese, a entrevistada admite que os governantes podem, mas não querem investir na melhoria do bairro, de forma que o representante dos moradores, embora empreenda algumas tentativas, não consegue, sozinho e sem apoio do poder público, fazer grandes transformações na realidade do Redenção.

revista brasileira educação ambiental 
Ao final da segunda entrevista, perguntou-se se o programa da AMAVISA tivesse dado certo, o que a entrevistada acredita que traria de positivo para 0 bairro. Ao que responde que o principal ponto seria o caminho de coleta específica para encaminhar os resíduos para reciclagem, cujos materiais seriam vendidos e o dinheiro revertido para a associação de moradores, para fazer melhorias no bairro. Nessa parte final da entrevista, a entrevistada deixa claro que têm conhecimento de que o caminhão não faz mais a coleta do lixo dos PEV, bem como enfoca a questão do benefício financeiro que a reciclagem dos resíduos do bairro traria em melhoria para os próprios moradores, auxiliando ainda a acarretar outros benefícios para a comunidade, caso fosse revertido para a associação de moradores.

A terceira entrevistada acredita que para fomentar essa conscientização, a divulgação é primordial, uma vez que, embora nem todos participem, os que participam geralmente se comprometem efetivamente. Porém, o estímulo inicial é facilmente deixado de lado se não há uma renovação, uma manutenção desse interesse, no cotidiano, no dia a dia dessa comunidade. A entrevistada também reclama sobre a rapidez com que acontecem os eventos, dizendo que a ação da AMAVISA the surpreendeu, e ela não teve o tempo que gostaria para se programar e fazer uma participação mais ativa e significativa no processo de Educação Ambiental do bairro. Comenta que gostaria de ter participado mais de palestras, atividades e da inauguração dos $\mathrm{PEV}$, pois sentiu falta da divulgação prévia do evento, o que ressalta insistentemente que não ocorreu. Em sua fala, deixa claro que existe a necessidade de continuidade da ação, já que a comunidade tende a deixar de lado caso não seja constantemente motivada, mesmo que desejassem fazê-lo. Ela consolida ainda sua percepção de que ações de Educação Ambiental deveriam ser uma parcela do cotidiano da comunidade, para que as ações não sejam esquecidas, mas, virem hábitos. Ao final, diz que tudo no bairro é esquecido, deixado de lado, demonstrando insatisfação com as condições gerais da comunidade. Novamente vêm à baila uma questão anteriormente levantada por outra entrevistada, de que Redenção é um bairro esquecido na cidade de Vitória do Santo Antão, abandonado à própria sorte pelos governantes da cidade e que é comum ter que ver as coisas serem iniciadas, mas nunca mantidas ou finalizadas nesse bairro. O que justifica essa sensação de abandono, falta de cuidado e atenção que é sentida pelos moradores.

Para o quarto entrevistado, a educação familiar é o que mais dificulta a aquisição da consciência ambiental e da educação vinda de outros meios. Retoma a metáfora de "quebrar as lixeiras", dizendo que se recebeu uma educação em casa que determina que isso é errado, não vai fazê-lo em espaços públicos. $O$ entrevistado bate na tecla de que a educação e a conscientização no âmbito familiar são os principais prejuízos para a ineficácia das práticas ambientais da população.

O entrevistado demonstra ter consciência sobre a importância da coleta seletiva e reciclagem para a sociedade e meio ambiente, mas se detém mais na questão do vandalismo com as lixeiras do que no ponto das ações de reciclagem. Quando

Revbea, São Paulo, V,13, № 1: 344-363, 2018. 
questionado sobre se a coleta é feita no bairro, insiste que não é feita porque quando chega não há lixeiras no local. O que demonstra que desconhece o fato de que o programa foi descontinuado e o caminhão de coleta seletiva não passa mais pelo bairro.

Sobre o uso dos PEV, o quarto entrevistado entende que as pessoas não separam o lixo adequadamente nos locais, mas que querem se livrar do lixo em suas casas e então colocam-nos nos pontos, o que para ele demonstra a falta de consciência da população. Ao final de sua entrevista, o entrevistado ainda comenta sua participação na distribuição de mudas de árvores pelo bairro:

Sobre as mudas que deixaram lá na associação, deixaram pra mais de 30 mudas. Essas mudas foram distribuídas pra os moradores, pra pessoas que iam praticar alguma atividade na associação, e elas mesmo pegaram as mudas e levaram pras suas casas. Algumas mudas foram colocadas no campo, ao redor do campo para que se tenha sombra futuramente. Essas mudas também foram colocadas na praça e foi rápido, a gente distribuiu muito rápido pra que as plantas não morressem, porque se ficassem lá iam ficar esquecidas. Dentro de 5 dias elas foram todas entregues aos moradores. Pior que eu não sei como estão essas plantas hoje, né?! Essas que foram entreguem aleatoriamente, mas creio que metade delas estão vivas. As da praça não vingaram porque como não tinha ninguém tomando conta, algumas ficaram sem água, outras as formigas comeram, outras [...] por não ter vigilância, algumas crianças jogando bola na praça pisaram e não sobreviveram [sic.] (Entrevistado 4, 2017).

O entrevistado demonstra ter participado ativamente da distribuição de mudas, mas ressalta novamente os prejuízos da descontinuidade dessas ações, pois após a plantação, as mudas não foram cuidadas e não se sabe quantas delas efetivamente sobreviveram. Nota-se aí a importância de perpetuar a conscientização para manter acesa a consciência ambiental.

A quinta entrevistada disse que para que houvesse a conscientização, as atividades tinham que ser permanentes, semanais ou, pelo menos mensais, a fim de manter a população engajada nas ações. Acredita também que a união da comunidade seria fundamental para a continuidade das ações, mas que 0 estímulo da AMAVISA ou de órgãos governamentais poderia oferecer o estímulo necessário para essa população. Sugere então a criação de uma rotina de atividades de Educação Ambiental no bairro, utiliza o termo "educação", no sentido de "chamar a população a se educar", o que denota sua crença de que a população possui a capacidade de se educar, cuja oportunidade de obter conhecimento se encontra nessa própria população. Também demonstra frustração ao dizer que mesmo que ela permaneça executando a coleta seletiva, se sente desanimada ao sentir que sua ação, isolada, não faz diferença. $A$ entrevista então diz que para efetivar a conscientização:

revista brasileira educação ambiental 
Deveria ter mais palestras pra incentivar mais o pessoal a fazer o que tem que ser feito: colocar o lixo no lixo. Infelizmente a maioria das pessoas não são educadas pra isso. Na verdade, a geração da gente não foi educada pra reciclar. A geração dos nossos filhos são educados pra reciclar, porém também não reciclam. E assim é uma associação de erros. Eu espero que pelo menos aqui em Redenção aja alguma coisa em relação a isso. Eu por exemplo, já desisti da associação dos moradores porque aqui a associação dos moradores e nada é a mesma coisa. Enfim, a gente espera que o poder político resolva, porém, a praça aqui de Redenção é um descaso total da prefeitura, independentemente de cor (partido) é um descaso total, eu acredito que Redenção é um bairro esquecido, porque não é um bairro turístico, um bairro muito visitado [...] [sic.] (Entrevistada 5, 2017).

A entrevistada finaliza os blocos de entrevista dizendo-se esperançosa em relação à ocorrência de mudanças positivas no quesito ambiental em seu bairro. Mas, não acredita que essa melhoria partirá da associação de moradores, acredita que o poder político pode fazer alguma mudança, mas critica o descaso dos partidos com o bairro. Ressalta ainda sua desmotivação em dar continuidade às próprias práticas de coleta seletiva e cuidado ambiental, por conta da descontinuidade das ações e do cuidado de outros problemas que ocorrem no bairro. Assim, pensa que uma nova ação teria de ganhar novamente a confiança da comunidade e ir, gradativamente, inserindo um processo educativo efetivo.

\section{Discussão dos resultados}

De maneira geral, foi possível entender que a amostra de pesquisa avaliada é concordante na insatisfação com a descontinuidade da ação de Educação Ambiental da AMAVISA, bem como acredita que por conta dessa descontinuidade, a ação como um todo de pouco ou nada valeu, pois não foi capaz de fomentar na população local uma conscientização efetiva sobre o meio ambiente.

Sobre o conhecimento da população em relação à coletiva seletiva e reciclagem, nota-se pouco conhecimento no geral, justamente o tema que foi eleito pela AMAVISA nessa ação. Assim, ao invés de encontrar diálogos ou ao menos entendimento sobre o significado das cores nos PEV para separar os resíduos, além de conhecimentos sobre os malefícios ambientais causados pelo acúmulo ou descarte inadequado de lixo, as doenças que podem ser transmitidas, entre outros tipos de entendimento que fariam parte da Educação Ambiental, também não foram observados. Portanto, se a ação da AMAVISA focou na coleta seletiva e na importância da reciclagem, a falta de conhecimento da população sobre questões relacionadas a esses dois temas, demonstra que a Educação Ambiental não foi efetivada. 
O trabalho de Matias e Pinheiro (2008), revela que o conhecimento é capaz de mudar o comportamento das pessoas e a concepção sobre o meio ambiente. $O$ homem passa a refletir sobre a sua relação com a natureza e 0 desenvolvimento.

Sobre a descontinuidade das ações de Educação Ambiental a AMAVISA alega não dispor de recursos humanos ou financeiros suficientes para manter uma ação desse porte em funcionamento em qualquer bairro. Justifica que que o apoio da prefeitura da cidade seria fundamental e que essa, inicialmente concordou em oferecer apoio, mas recuou e não continuou com a colaboração.

Nota-se que o tempo é uma variável fundamental no processo educacional, contudo, como foi possível observar nos relatos dos participantes, a comunidade foi pontualmente motivada a empreender ações de coleta seletiva e reciclagem, mas esse estímulo durou muito pouco para que se tornasse um aprendizado, para que virasse um saber e um hábito.

Em relação a essa percepção central que foi retirada dos resultados obtidos, de que faltou tempo para que a comunidade fomentasse uma aprendizagem social relacionada à Educação Ambiental, vale evocar as percepções de Del Prette (2005), que fala sobre o treinamento de habilidades sociais e como ele é calcado por um referencial teórico-prático que envolve conceitos e também procedimentos de avaliação-intervenção. Esses que são desenvolvidos partindo de estudos no campo da psicologia cognitivocomportamental, na teoria da aprendizagem social, por meio de abordagens sistêmicas e ecológicas, entre outros métodos, com a união de estudiosos que se interessam pelo tema e que buscam recursos para desenvolver comportamentos necessários ao ajustamento social, saúde e qualidade de vida.

Sobre a ausência de engajamento governamental no cuidado com as ações voltadas ao meio ambiente no bairro e na cidade, é possível embater com questões que envolvem a gestão ambiental nas cidades. Em relação a isso, a Agenda 21 (1997) aponta que após um tempo de governos altamente afastados da questão ambiental na gestão de cidades, o Brasil retomou essa preocupação, elaborando premissas que vigoram a fim de reconstruir as cidades de maneira estratégica-ecológica e visão do entorno, que são colocadas tanto por parte de ambientalistas - com ideias de capacidade de suporte, pegada ecológica, equilíbrio energético, conforto ambiental, entre outras ações. Além de por meio de urbanistas, cujo enfoque sobre as cidades e contribuição para 0 fortalecimento de organizações sociais.

Ainda sobre esse ponto, Santos (2000) explica que cada vez é mais notável que o destino dos esforços de renovação ou reconversão terminou por ser o de frustrar, em maior ou menor grau, os protagonistas, a proporção de suas expectativas. Nesse bojo, passou-se a falar sobre o planejamento regulatório convencional, que ficou fragilizado gradualmente, debilitando-se no bojo do welfare state e, em países 'semi' periféricos, tal como o Brasil, da noção de Estado desenvolvimentista. Neste sentido, o autor prossegue dizendo que, diante de tal cenário, o desenvolvimento urbano sustentável já deixou de ser uma

revista brasileira educação ambiental 
resposta velada às necessidades de planejamento urbano. Na realidade, imputou uma ótica hegemônica a fim de tentar fomentar uma 'atualização ecológica' de um padrão capitalista de 'desenvolvimento' urbano.

Para Souza (2000) se a ideia-ação central do planejamento urbano regulatório convencional era tão somente modernizar o espaço urbano complementando-se com ideias-ação como ordem, racionalidade, entre outras no desenvolvimento urbano sustentável a ideia-ação central torna-se um tipo de modernização alinhada à proteção ambiental. De modo que, é só refletir sobre o mainstream da corrente do desenvolvimento sustentável, como um todo - cujo autor cita como exemplo o Relatório de Brundtland, que distante de problematizar o modelo social capitalista, toma o crescimento econômico de maneira simplista, como uma ação inevitável sem a qual a pobreza não poderia ser dizimada.

Assim, na agenda 21 (1997) dispõe-se sobre a retomada de um planejamento estratégico participativo e multisetorial, partindo de uma construção coletiva. De forma que a gestão urbana passe a se operacionalizar por meio de planos diretores e similares, cuja visão integradora entre o âmbito rural e urbano, possibilitem uma validação de municípios enquanto espaços dinâmicos e interdependentes, tomando como referência de análise outros arranjos espaciais e sócio funcionais, tais como os comitês de bacia, consórcios municipais, entre outros, como suas premissas de sustentabilidade. Ainda de acordo com a publicação, demais fatores importantes nessa concepção fazemse necessários, bem como as inserções de custos ambientais e sociais nos projetos de infraestrutura, promoção de mudança de comportamento individual para o coletivo e internalização de hábitos novos de consumo, que sejam mais saudáveis, além do uso do espaço urbano com evitando o desperdício, entre demais formas de consumo urbano.

A Agenda 21 (1997) expõe ainda que a mudança do modelo atual de cidade, demanda esforços coletivos, uma vez que perpassa por uma premissa mais ampla de transformação em sociedades sustentáveis, com suas peculiaridades sócio ambientais, produtivas e essencialmente culturais preservadas. Tal eixo de estratégia, contudo, não visa desestimular a execução de atividades e ações menores a fim do alcance de objetivos, tomando como instrumentos essencial a educação formal e não formal da população. Explica ainda que os governos devem assumir princípios de sustentabilidade como eixos estratégicos que norteiam suas políticas públicas, bem como os cidadãos devem mudar seus hábitos em atitudes em relação ao espaço urbano. Torna-se preciso então aprender a minimizar o consumo de água e energia, eleger produtos locais, optar pelo transporte coletivo, gerar menores quantidades de resíduos, entre outras ações. Todavia, a participação democrática deve ser plenamente assegurada por normas legitimadas no processo político e empoderamento pela sociedade local, possibilitando que sejam praticadas por instituições públicas, no trabalho de integração partindo de enfoques setoriais, caso contrário, o risco iminente é de que não sejam inclusas enquanto prioridades no âmbito da sustentabilidade as demandas por justiça social e também ambiental. 
Em vista deste contexto, Del Prette et al. (2005) acreditam que o campo de treinamento de habilidades sociais pode ser explorado e adaptado a um enfoque mais sistêmico. De forma que pode imputar significativas contribuições e trazê-las para o contexto da Educação Ambiental, acenando com um grupo de possibilidades que podem ser estudadas de maneira melhor e mais profunda, bem como aplicadas em situações do cotidiano da população.

Foi percebido neste estudo o impacto negativo social que uma ação de Educação Ambiental é capaz de causar se interrompida bruscamente. Desta maneira, corrobora com o estudo de Galbiati (2012), que relata que algumas atitudes positivas provenientes da população no sentido de separar em sua residência os resíduos sólidos, acabam se descontinuando, isso acontece devido à falta de um programa de coleta seletiva continuado, desse modo fazendo a mesma população acreditar que tais ações não tenham utilidade nem importância para a construção da cidadania.

As estratégias de Educação Ambiental devem ser fundamentadas objetivando uma satisfatória gestão ambiental em seja qual for a localidade, estas devem ser um instrumento para as pessoas refletirem e mudarem suas atitudes, dessa forma a sociedade assume o compromisso de melhorar o meio ambiente ao qual está inserida (PELICIONI, 2004).

Segundo Morin (2003), as práticas educativas devem focar nas mudanças de hábitos, práticas sociais, atitudes, capacidade de avaliação, desenvolvimento de competências e participação efetiva dos aprendizes. Isto instiga a sociedade a compor novos conhecimentos que proporcionem "uma reforma do pensamento".

Sendo assim, corrobora-se com esses achados teóricos, a percepção de que a cidade em questão demanda de uma integração de forças para que suas ações de desenvolvimento sustentável sejam efetivadas e levadas adiante. Ao passo que, em relação à conscientização da sociedade, é necessário contar com uma ação contínua de educação para desenvolver a habilidade social de preservação ambiental.

\section{Conclusão}

É lamentável a falta de empenho dos gestores municipais no que diz respeito ao apoio dos projetos de Educação Ambiental, visto sua importância no decorrer do estudo. Na cidade da Vitória de Santo Antão existe uma comunidade carente de Educação Ambiental, de estímulos ao desenvolvimento intelectual e crítico, de um olhar holístico, de gestores engajados a entender os motivos de algumas campanhas educativas não prosperarem e investirem e se comprometerem para estas ações de Educação Ambiental continuarem. Apenas dessa forma haverá de fato uma mudança de hábito na população, refletindo no bem do ecossistema e preservação da biodiversidade.

revista brasileira

educação ambiental 


\section{Referências}

ABDALA W.J.S.; et al. Educação Ambiental e coleta seletiva: importância e contextualização no mundo atual. Revista Travessias. n ․ 2. 2008.

AZEVEDO, D.S.; et al. Resíduos sólidos: diagnóstico e proposições para o bairro de Redenção, no município de Vitória de Santo Antão/PE. InterEspaço, Grajaú/MA, v. 2, № 5, p. 424-445, jan./abr. 2016.

BARDIN, L. Análise de Conteúdo. Tradução Luís Antero Reto e Augusto Pinheiro. 70. ed. p. 37. 2010.

BESERRA, E.P.; ALVES, M.D.S.; PINHEIRO, P.N.C.; VIEIRA, N.F.C. Educação Ambiental e enfermagem: uma integração necessária. Rev. bras. enferm. v.63, no $\quad 5, \quad$ p. $\quad 848-852.2010 .2$ Disponível em <http://www.scielo.br/pdf/reben/v63n5/26.pdf>. Acesso em: fev. 2016.

BRASIL. Secretaria Nacional de Saneamento Ambiental. Panorama do Saneamento Básico no Brasil: Elementos conceituais para o saneamento básico.Brasília; Ministério das Cidades; v. 1. p. 36. 2009. Disponível em: $<$ http://bibspi.planejamento.gov.br/bitstream/handle/iditem/271/PANORAMAVol 1.pdf? sequence $=1>$. Acesso em: dez. 2015

BRASIL. Ministério da Saúde. Conselho Nacional de Saúde. Comissão Nacional de Ética em Pesquisa. Resolução n. 466/12 sobre pesquisa envolvendo seres humanos. Brasília-DF, 2012.

BRASIL. AGENDA 21. Conferência das Nações Unidas sobre meio ambiente e desenvolvimento. São Paulo: Secretaria de Estado do Meio Ambiente, 1997.

BRASIL. Presidência da República. Casa Civil. Subchefia para Assuntos Jurídicos. Lei $n^{\circ}$ 9.795, de 27 de abril de 1999. Dispõe sobre a Educação Ambiental, institui a Política Nacional de Educação Ambiental e dá outras providências. Brasília: Diário Oficial da União, seção 1, 28 abr. p. 1. 1999.

DEL PRETTE, Z.A.P. Avaliação do repertório social de crianças com necessidades educacionais especiais. In: MENDES, E.G.; et al. (Eds.), Temas em Educação Especial: Avanços recentes. São Carlos, Brasil: EDUFSCar, p. 149-158.2004.

DEL PRETTE, Z.A.P.; DEL PRETTE, A. Psicologia das habilidades sociais: Terapia e educação. Petrópolis, Brasil: Vozes, 1999.

DEL PRETTE, Z.A.P., PAIVA, M.L.M.F.; DEL PRETTE, A. Contribuições do referencial das Habilidades Sociais para uma abordagem sistêmica na compreensão do processo de ensino-aprendizagem. Interações, v.10, n.20, dez. 2005, p. 45-56.

DENZIN, N.K.; LINCOLN, Y. S. (eds). Handbook of qualitative research. Thousand Oaks: Sage Publications; 1994.

FREIRE, P. Conscientização: teoria e prática da libertação - uma introdução ao pensamento de Paulo Freire. 3. ed. São Paulo: Cortez \& Moraes, 1980. 
GALBIATI, A.F. O Gerenciamento Integrado de Resíduos Sólidos e a Reciclagem. Educação Ambiental para o Pantanal, 2005.

GIL, A. C. Métodos e técnicas da pesquisa social. Ed. Atlas, 5. ed. São Paulo, p. 220, 2008.

GOMES, R. Análise e interpretação de dados de pesquisa qualitativa. In: MINAYO, M.C.S. (Org.). Pesquisa social: teoria, método e criatividade. 26. ed. Petropólis: Vozes, p. 79-108. 2007.

MATIAS, H.J.D.; PINHEIRO, J.Q. Desenvolvimento sustentável: um discurso sobre a relação entre desenvolvimento e natureza. Revista Psicologia e Sociedade, Porto Alegre, v. 20, n. 1, p.134-143, 2008.

PELICIONI, M.C.F. Controle ambiental de resíduos: curso de gestão ambiental Barueri. São Paulo: Manole, 2004.

SANTOS, M. Por uma outra globalização: do pensamento único à consciência universal. Rio de Janeiro: Record, 2000.

SINGER, P. A recente ressurreição da economia solidária no Brasil. In: SANTOS, B.S. (Org.) Produzir para viver: os caminhos da produção não capitalista. Rio de Janeiro: Civilização Brasileira,p.81-126. 2002.

SISSINO, C.S. Resíduos sólidos, ambiente e saúde: uma visão multidisciplinar. Rio de Janeiro: Ed. Fiocruz, 2000.

SOUZA, M.L. O planejamento e a gestão das cidades em uma perspectiva autonomista. Revista Território, Rio de Janeiro, ano V, na 8, p. 67-100, jan/Jun., 2000. 